\title{
How Accurately Contemporary Models Can Predict Monsoons?
}

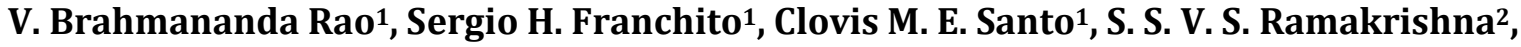 \\ Julio P. R. Fernandez ${ }^{1}$ \\ ${ }^{1}$ Center for Weather Prediction and Climate Studies, INPE, São José dos Campos, Brazil \\ ${ }^{2}$ Department of Meteorology and Oceanography, Andhra University, Visakhapatanam, India \\ Email: raovtz@yahoo.com.br
}

How to cite this paper: Brahmananda Rao, V., Franchito, S.H., Santo, C.M.E., Ramakrishna, S.S.V.S. and Fernandez, J.P.R. (2018) How Accurately Contemporary Models Can Predict Monsoons? American Journal of Climate Change, 7, 97-113. https://doi.org/10.4236/ajcc.2018.71008

Received: December 7, 2017

Accepted: March 27, 2018

Published: March 30, 2018

Copyright (c) 2018 by authors and Scientific Research Publishing Inc. This work is licensed under the Creative Commons Attribution International License (CC BY 4.0).

http://creativecommons.org/licenses/by/4.0/

\section{cc) (i) Open Access}

\begin{abstract}
Seasonal changes exhibit climate changes, so models can predict future climate change accurately only if they can reproduce seasonal cycle accurately. Further, seasonal changes are much larger than the changes even in long period of centuries. Thus it is unwise to ignore large ones compared to small climate change. In this paper, we determine how accurately a suite of ten coupled general circulation models reproduce the observed seasonal cycle in rainfall of the tropics. The seasonal cycles in rainfall of global tropics are known as monsoons. We found that the models can reasonably reproduce the seasonal cycle in rainfall, thus are useful in climate prediction and simulation of global monsoons.
\end{abstract}

\section{Keywords}

Climate Change, Monsoons, Seasonal Change, Tropical South America and India Rainfall, Coupled General Circulation Models, Projections of Future Climate, IPCC Models

\section{Introduction}

Future climate change can be due to internal and external variability [1]. In a recent study, [2] noted that the observed trends of climate change are very unlikely attributed to internal variability even if the contemporary climate models are found to underestimate it. The future projection of climate change obtained by state-of-art models may be uncertain mainly because of the difficulty in the determination of quantitative and spatial distribution of future greenhouse gases and other radiatively important external parameters. Also the knowledge how 
the climate system responds to these external influences is still incomplete. To complicate further it is uncertain how useful can a model be for climate change studies if its numerous parameters are tuned to present climate [3]. Since seasonal changes display climate changes, the ability of a model to reproduce the seasonal cycles is a positive indication that the model can also be used for the investigation of climate change [3]. Thus models can predict future climate accurately only if they can reproduce seasonal cycles accurately. Also the seasonal changes for example in surface air temperature, are much larger than the changes in the long periods, even centuries and it is unwise to ignore large ones compared to small climate shifts.

In the extra-tropics surface air temperature determines well the climate and climate change, while in the tropics rainfall variations are of greater significance. [4] determined the changes the phase and amplitude of the annual cycle of surface air temperature in extra tropics and found an advance of 1.7 days in phase for the land area between 1954 and 2007. They also found significant changes in the amplitude. None of the IPCC 5 models reproduce the shift towards earlier seasons. However, [4] examined only the annual cycle. But the seasonal shift is given not only by the first harmonic of 12 months period but the other higher harmonics also contribute to the seasonal shift.

Billions of people around the world in the tropics depend crucially on the rainfall for their survival. The seasonal cycles in precipitation of the tropics are known as monsoons, the most energetic part of tropical climate system. Here we find the veracity of IPCC models to reproduce the observed seasonal cycles in precipitation in the tropics, thus finding how accurately the models can predict climate change. For this purpose we calculated the amplitude and phase of the first four harmonics (not only the first) in the rainfall over land area from 10 IPCC models: Miroc3.2 [5], CCSM3 [6], HadCM3 [7], ECHAM5 [8], Mk3.0 [9], CGCM2.3.2 [10], CM4 [11], BCM2.0 [12], CGCM3 [13] and CM3.0 [14]. Such an analysis also gives an idea how accurately the present state-of-art models reproduce the global monsoons. We determine the accuracy with which a suite of ten coupled atmospheric general circulation models reproduce the observed seasonal cycles in rainfall. This gives an idea how well these models can predict climate change.

\section{Data Sources}

For the land area of the tropics $\left(50^{\circ} \mathrm{N}-50^{\circ} \mathrm{S}\right)$ the rainfall data were obtained for the period 1960-1990 from the University of Delaware (1950-1999) [15]. We calculated the amplitude and phase of the first four harmonics in the rainfall over land area from 10 IPCC models

(http://www.ipcc-data.org/ar4/gcm_data.html) (see Table 1). The first four harmonics were obtained from 30 years mean monthly rainfall using the Fourier series. The calculation of amplitude and phase using the Fourier series ensures their determination by least square method [16]. 
Table 1. Ten IPCC models used in the study.

\begin{tabular}{|c|c|c|}
\hline & IPCC ID & Source \\
\hline MIROC3.2 & $\begin{array}{c}\text { Model for Interdisciplinary } \\
\text { Research on Climate (MIROC), } \\
\text { version } 3.2\end{array}$ & $\begin{array}{l}\text { Atmosphere and Ocean } \\
\text { Research Institute, } \\
\text { University of Tokyo, Japan }\end{array}$ \\
\hline CCSM3 & $\begin{array}{c}\text { Community Climate System } \\
\text { Model, version } 3\end{array}$ & $\begin{array}{c}\text { National Center for Atmospheric } \\
\text { Research (NCAR), USA }\end{array}$ \\
\hline HadCM3 & $\begin{array}{l}\text { Hadley Centre Coupled } \\
\text { Model, version } 3\end{array}$ & Met Office Hadley Centre, UK \\
\hline ECHAM5/MPI-OM & $\begin{array}{l}\text { European Center Hamburg } \\
\text { Model, version } 5\end{array}$ & $\begin{array}{c}\text { Max Planck Institute for } \\
\text { Meteorology (MPI), Germany }\end{array}$ \\
\hline Mk3.0 & Mark, version 3.0 & $\begin{array}{l}\text { Commonwealth Scientific and } \\
\text { Industrial Research Organisation } \\
\text { (CSIRO), Australia }\end{array}$ \\
\hline CGCM2.3.2 & $\begin{array}{l}\text { Coupled Atmosphere-Ocean } \\
\text { General Circulation } \\
\text { Model, version 2.3.2 }\end{array}$ & $\begin{array}{l}\text { Meteorological Research } \\
\text { Institute (MRI), Japan }\end{array}$ \\
\hline CM4 & $\begin{array}{l}\text { Coupled Global Climate } \\
\text { Model, version } 4\end{array}$ & $\begin{array}{l}\text { Centre National de Recherches } \\
\text { Meteorologiques (CNRM), France }\end{array}$ \\
\hline BCM2.0 & $\begin{array}{c}\text { Bergen Climate } \\
\text { Model (BCM) Version } 2\end{array}$ & $\begin{array}{l}\text { Bjerknes Centre for Climate Research } \\
\text { (BCCR), Univ. of Bergen, Norway }\end{array}$ \\
\hline CGCM3 & $\begin{array}{l}\text { Coupled Global } \\
\text { Model, version } 3\end{array}$ & $\begin{array}{c}\text { Canadian Centre for } \\
\text { Climate Modelling and } \\
\text { Analysis (CCCma), Canada }\end{array}$ \\
\hline CM3.0 & $\begin{array}{l}\text { Coupled Global Climate } \\
\text { Model, version } 3\end{array}$ & $\begin{array}{l}\text { Institute of } \\
\text { Numerical Mathematics } \\
\text { (INM), Russia }\end{array}$ \\
\hline
\end{tabular}

\section{Results and Discussion}

The left hand side of Figure 1 shows the observed annual, January and July rainfall. January and July represent the typical boreal winter and summer and austral summer and winter months respectively. Thus the change in rainfall between these two months gives the seasonal change. The middle figure shows the corresponding rainfall in multi model ensemble (MME) of the 10 Models. The right hand side shows the standard deviation amongst the 10 models.

In observations, (top of Figure 1) the principle regions of rainfalls the Amazon basin, Congo basin and Indonesia can be seen in the annual mean. In the MME these three regions are reproduced well. But, there are quantitative differences both in magnitude and spatial extension, particularly over western Amazon region. Top right side figure shows variations amongst the ten models, again over western Amazon and Indonesia, varying from 1.5 - 2.5 per day. The models seem to have difficulty in obtaining the correct rainfall near mountainous region such as Andes and Himalaya. The generally high (low) rainfall in summer (winter) months of northern and southern hemispheres can be seen in the middle and bottom figures, thus simulating the seasonal variations. The monsoonal 

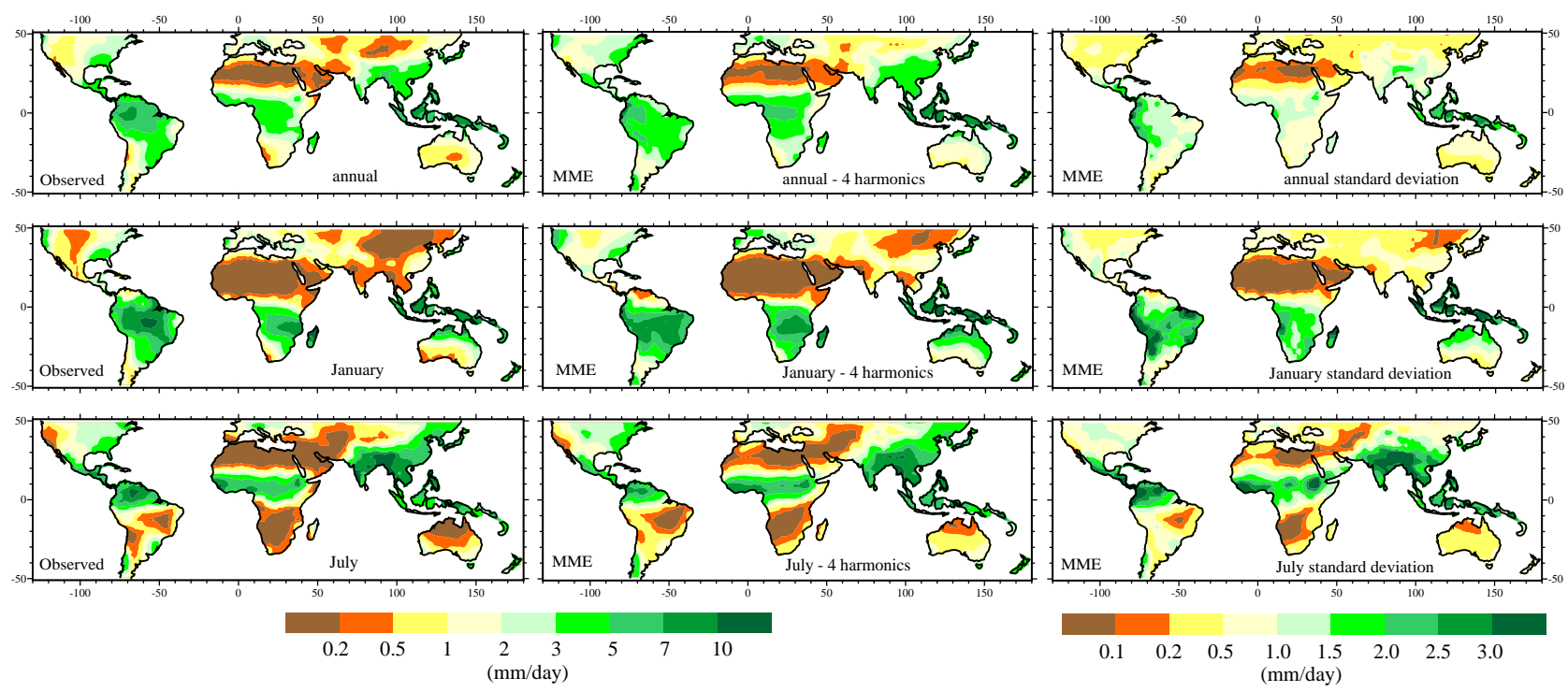

Figure 1. Left hand side upper figure: Observed annual rainfall in $\mathrm{mm} /$ day; Middle figure: Observed January rainfall in $\mathrm{mm} / \mathrm{day}$; Lower figure: Observed July rainfall in $\mathrm{mm} /$ day.

rainfall variations are reproduced well in January and July by MME, for example, the east Asian Indian and South American monsoon regions show high (low) rainfall in summer (winter).

Figure 2 shows the variance explained by the first two (annual and semiannual) harmonics both in observations and MME. The lower figure shows the sum of the variance of the first two harmonics. It is clear from the figure that at least the first two harmonics are necessary to explain high percentage of variance of the annual variation of rainfall. Some studies of global monsoons [17] [18] included only the annual (first) harmonic.

Figure 3(a) and Figure 3(b) show respectively the amplitude (h1 and h2) and phase $(\varphi 1$ and $\varphi 2)$ of the first and second harmonics in the observations and MME and the difference between the two. In the lower part of the Figure 3(a) (left figure) MME seem to reproduce the amplitude values reasonably well over subtropical regions of South America, Africa and Australia and also over the tropical South America and India, while there are phase differences (right figure) of 10 days or more over some regions. In Figure 3(b), it can be seen that the amplitude of the second harmonic is substantial. [19] noted the important of the semi-annual component over Indian monsoon region. The MME showed the high amplitude in semi-annual component over western Amazonia and Congo basin. The lower part of the Figure 3(b) shows in some specific regions there are some differences between the observations and MME both in amplitude and phase of semi-annual component.

The root mean square (RMS) error, absolute error (ABSE) and the bias the models make with respect to observations in determining the amplitude and phase of the first four harmonics and mean annual rainfall are given Table 2, for the 10 models and MME. Also given are the spatial correlation coefficients (CC) between the observed and model amplitudes and phases. In general errors are 

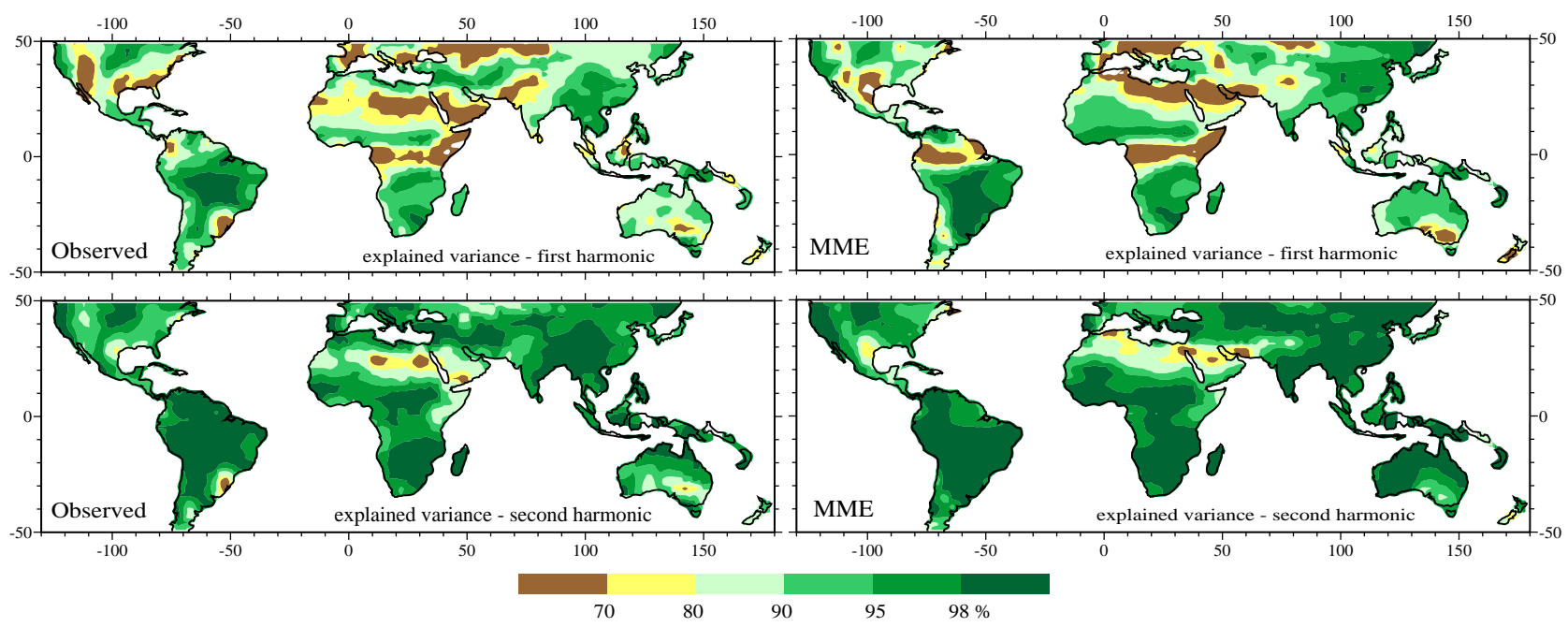

Figure 2. Observed and MME variance explained by first and second (annual and semiannual) harmonics.
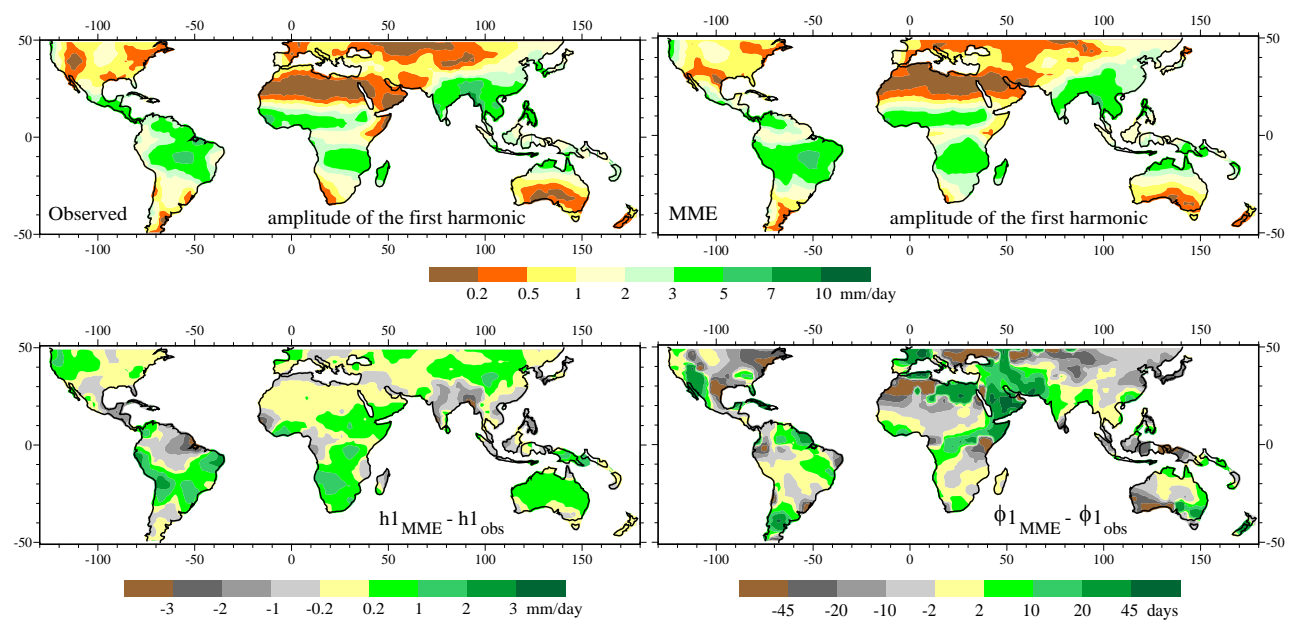

(a)
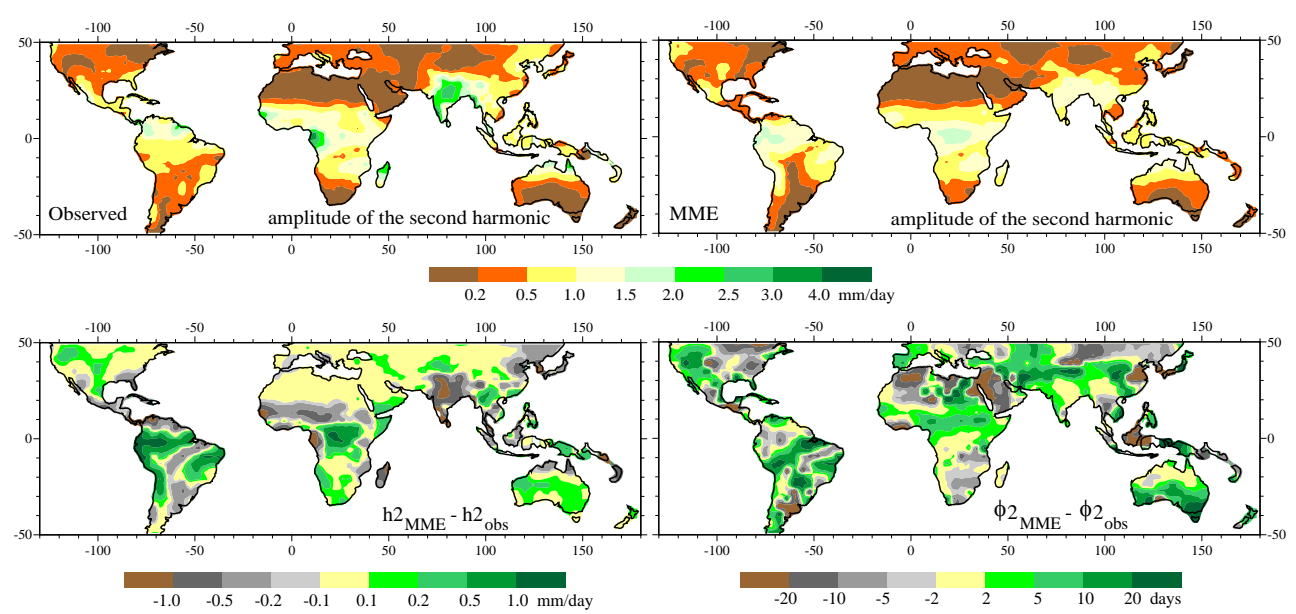

(b)

Figure 3. (a) Upper figure: Observed and MME amplitude of first (annual) harmonic; Lower figure: left hand side: the difference between the amplitude of first (annual) harmonic in MME and the observations; right hand side: difference in phase between the observations for the first (annual) harmonic; (b) Same as the (a) except for the second harmonic. 
Table 2. Bias, ABSE and RMSE and correlation in the spatial distribution of rainfall between the observed and the ten models. Last rows: grid size of models.

\begin{tabular}{|c|c|c|c|c|c|c|c|c|c|c|c|c|}
\hline \multicolumn{2}{|c|}{ Model } & MIROC3.2 & CCSM3 & HadCM3 & ECHAM5 & Mk3.0 & CGCM2.3.2 & CM4 & BCM2.0 & CGCM3 & CM3.0 & MME \\
\hline \multirow{4}{*}{ 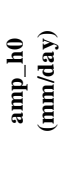 } & Bias & 0.60 & 0.10 & 0.30 & 0.00 & -0.20 & 0.30 & 0.40 & 0.50 & 0.00 & -0.10 & 0.30 \\
\hline & ABSE & 1.10 & 1.00 & 0.80 & 0.80 & 0.90 & 0.90 & 1.10 & 1.10 & 0.80 & 1.00 & 0.70 \\
\hline & RMSE & 1.70 & 1.40 & 1.70 & 1.30 & 1.50 & 1.30 & 1.50 & 1.60 & 1.20 & 1.40 & 1.00 \\
\hline & Correl & 0.78 & 0.75 & 0.78 & 0.80 & 0.72 & 0.79 & 0.74 & 0.73 & 0.79 & 0.72 & 0.88 \\
\hline \multirow{4}{*}{ 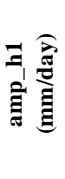 } & Bias & 0.40 & 0.00 & 0.30 & -0.10 & 0.00 & 0.30 & 0.40 & 0.40 & 0.00 & -0.20 & 0.00 \\
\hline & ABSE & 0.90 & 0.90 & 0.80 & 0.70 & 0.80 & 0.80 & 1.00 & 1.00 & 0.70 & 0.90 & 0.60 \\
\hline & RMSE & 1.40 & 1.40 & 1.50 & 1.20 & 1.30 & 1.30 & 1.50 & 1.50 & 1.20 & 1.30 & 0.80 \\
\hline & Correl & 0.76 & 0.64 & 0.74 & 0.76 & 0.70 & 0.78 & 0.63 & 0.67 & 0.74 & 0.67 & 0.86 \\
\hline \multirow{4}{*}{ 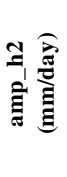 } & Bias & 0.10 & 0.10 & 0.10 & 0.00 & 0.10 & 0.10 & 0.20 & 0.10 & 0.10 & 0.00 & 0.00 \\
\hline & ABSE & 0.40 & 0.50 & 0.40 & 0.30 & 0.40 & 0.40 & 0.50 & 0.40 & 0.40 & 0.40 & 0.30 \\
\hline & RMSE & 0.70 & 0.70 & 0.70 & 0.60 & 0.70 & 0.70 & 0.80 & 0.70 & 0.60 & 0.60 & 0.50 \\
\hline & Correl & 0.59 & 0.44 & 0.60 & 0.63 & 0.54 & 0.59 & 0.40 & 0.49 & 0.60 & 0.55 & 0.69 \\
\hline \multirow{4}{*}{ 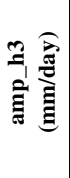 } & Bias & 0.10 & 0.10 & 0.10 & 0.00 & 0.10 & 0.10 & 0.10 & 0.10 & 0.10 & 0.10 & 0.00 \\
\hline & ABSE & 0.20 & 0.30 & 0.20 & 0.20 & 0.20 & 0.30 & 0.20 & 0.20 & 0.20 & 0.20 & 0.10 \\
\hline & RMSE & 0.40 & 0.40 & 0.50 & 0.30 & 0.40 & 0.40 & 0.40 & 0.40 & 0.30 & 0.40 & 0.20 \\
\hline & Correl & 0.58 & 0.35 & 0.51 & 0.49 & 0.48 & 0.49 & 0.44 & 0.47 & 0.48 & 0.34 & 0.63 \\
\hline \multirow{4}{*}{ 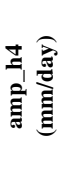 } & Bias & 0.00 & 0.00 & 0.10 & 0.00 & 0.00 & 0.10 & 0.10 & 0.10 & 0.00 & 0.00 & 0.00 \\
\hline & ABSE & 0.10 & 0.20 & 0.20 & 0.10 & 0.10 & 0.20 & 0.20 & 0.20 & 0.10 & 0.10 & 0.10 \\
\hline & RMSE & 0.20 & 0.20 & 0.30 & 0.20 & 0.20 & 0.20 & 0.30 & 0.30 & 0.20 & 0.20 & 0.10 \\
\hline & Correl & 0.49 & 0.39 & 0.47 & 0.55 & 0.50 & 0.48 & 0.33 & 0.45 & 0.44 & 0.43 & 0.60 \\
\hline \multirow{4}{*}{ 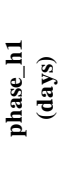 } & Bias & 0.00 & -5.50 & -0.30 & -3.40 & -0.40 & -0.90 & -1.90 & -1.10 & -1.90 & -5.40 & -1.90 \\
\hline & ABSE & 14.30 & 21.60 & 17.00 & 18.40 & 20.30 & 17.60 & 19.60 & 17.90 & 16.60 & 25.30 & 15.60 \\
\hline & RMSE & 23.60 & 32.40 & 26.10 & 28.70 & 29.20 & 27.30 & 30.60 & 29.70 & 25.40 & 36.30 & 26.80 \\
\hline & Correl & 0.92 & 0.86 & 0.90 & 0.89 & 0.87 & 0.89 & 0.86 & 0.87 & 0.90 & 0.83 & 0.89 \\
\hline \multirow{4}{*}{ 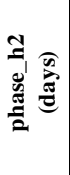 } & Bias & 1.00 & -0.10 & -0.10 & -0.20 & -0.50 & 2.00 & 3.00 & 1.70 & 0.60 & 2.20 & 0.50 \\
\hline & ABSE & 13.00 & 14.60 & 11.90 & 11.60 & 14.20 & 14.90 & 13.90 & 13.90 & 13.40 & 15.20 & 10.40 \\
\hline & RMSE & 17.70 & 18.70 & 16.60 & 15.90 & 18.90 & 19.60 & 18.20 & 18.30 & 17.80 & 19.70 & 15.00 \\
\hline & Correl & 0.83 & 0.85 & 0.85 & 0.86 & 0.83 & 0.80 & 0.85 & 0.85 & 0.84 & 0.81 & 0.88 \\
\hline \multirow{4}{*}{ 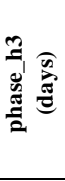 } & Bias & 1.40 & 0.10 & 0.50 & -1.10 & 1.50 & 1.30 & 2.20 & 2.60 & 1.40 & 1.50 & 1.60 \\
\hline & ABSE & 10.40 & 11.90 & 10.30 & 10.40 & 11.10 & 11.00 & 11.80 & 10.50 & 10.50 & 12.70 & 8.10 \\
\hline & RMSE & 13.20 & 14.50 & 13.20 & 13.10 & 13.80 & 13.50 & 14.40 & 13.20 & 13.40 & 15.30 & 10.80 \\
\hline & Correl & 0.79 & 0.72 & 0.79 & 0.79 & 0.76 & 0.79 & 0.78 & 0.79 & 0.78 & 0.75 & 0.84 \\
\hline \multirow{4}{*}{ 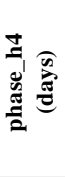 } & Bias & 1.00 & 0.20 & 0.40 & -0.90 & 1.20 & -0.10 & 2.30 & 1.10 & -0.30 & 1.40 & 0.80 \\
\hline & ABSE & 9.00 & 10.70 & 8.90 & 9.40 & 9.40 & 9.90 & 10.50 & 9.70 & 9.10 & 10.20 & 8.20 \\
\hline & RMSE & 10.90 & 12.60 & 11.00 & 11.20 & 11.30 & 11.80 & 12.20 & 11.60 & 11.20 & 11.90 & 10.20 \\
\hline & Correl & 0.76 & 0.72 & 0.77 & 0.75 & 0.76 & 0.74 & 0.73 & 0.73 & 0.72 & 0.75 & 0.75 \\
\hline \multirow{2}{*}{$\begin{array}{l}\text { grid } \\
\text { size }\end{array}$} & $\operatorname{long}^{0}$ & 1.125 & 1.40 & 1.825 & 1.825 & 1.825 & 2.81 & 2.81 & 2.81 & 3.75 & 5.00 & 3.75 \\
\hline & lat $^{0}$ & 1.120 & 1.40 & 1.250 & 1.860 & 1.860 & 2.81 & 2.81 & 2.81 & 3.75 & 4.00 & 3.75 \\
\hline
\end{tabular}

relatively less and CC are higher for the MME. High CC of 0.88 is found for the MME with mean annual rainfall. In the case of the annual harmonic the CC is 0.86. Even in the case of other harmonics CCs are high for MME. This shows that the MME is able to reproduce global monsoons well. Even in the case of some individual models the CCs are high. All the models seem to do well in re- 
producing mean annual rainfall. Although the models have some difficulty in reproducing the amplitude of the four harmonics, they seem to do well in reproducing phases. Note that the CCs are high for the phases. This means that all the models and MME do well in reproducing the phase of global monsoons such as onset and withdrawal.

Now we examine how these models and MME perform for the regional monsoons over India and South America.

\subsection{India Monsoon}

Figure 4 is similar to Figure 1. A comparison of top left hand side and middle
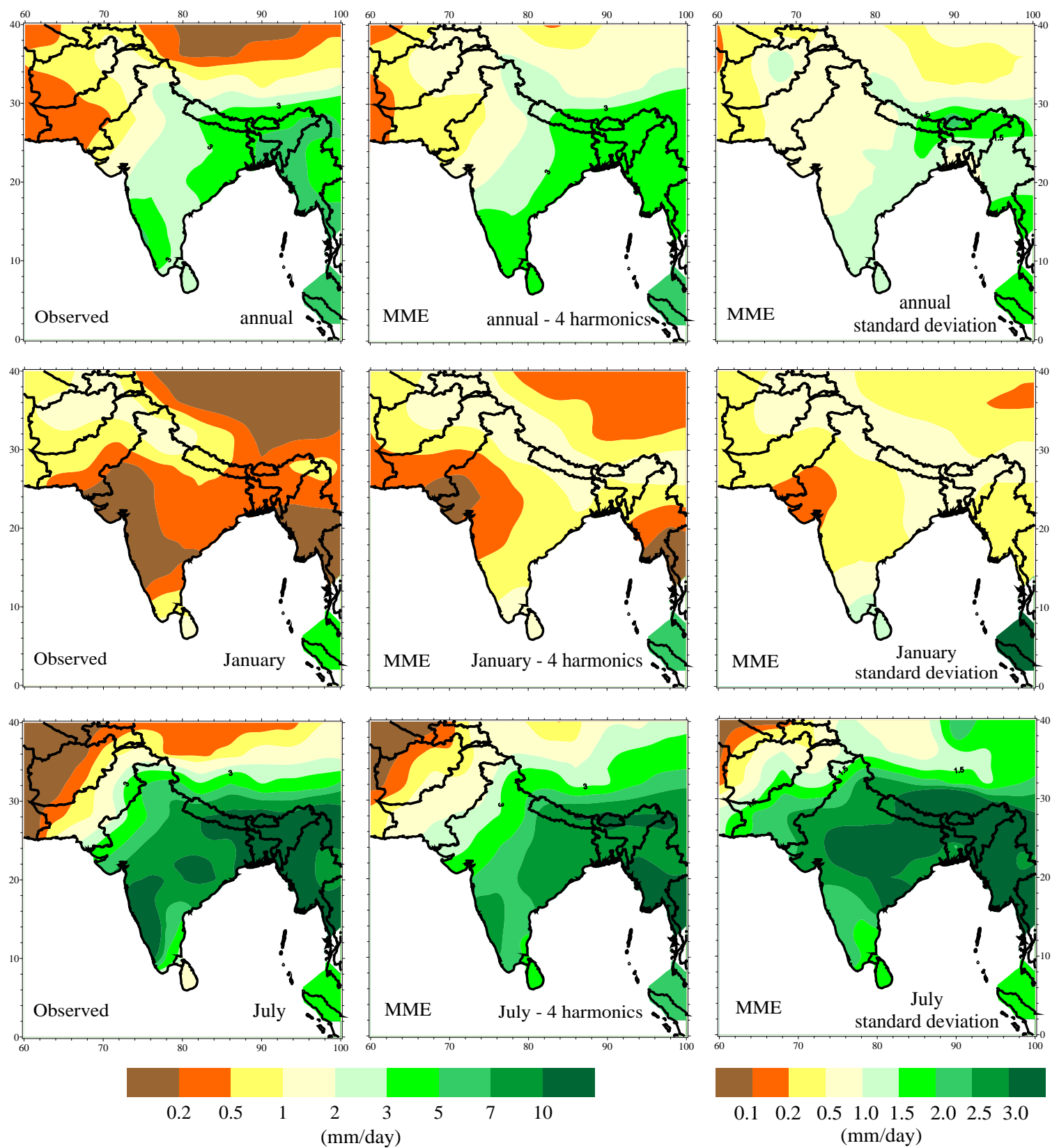

Figure 4. Same as Figure 1, but for the Indian monsoon. 
figures shows that the MME is able represent the general patterns of variations of annual rainfall, although there are regional differences. The Western Peninsular maximum is reproduced well. But the MME over estimates rainfall in southeastern peninsula. Top right hand side figure shows that there are variations in the models with maximum variations around $30^{\circ} \mathrm{N}$ around $90^{\circ} \mathrm{E}$.

Middle figure shows that the MME has some difficulty in reproducing the January rainfall quantitatively although there is qualitative agreement. Except over the Gujarat state and around the standard deviation amongst the models is small.

The lower figure shows that in the principal summer monsoon month, July there is over all agreement between the observations and the MME in the rainfall although there are some regional differences. The lower right hand side figure shows that in central India there are large differences amongst the models.

Figure 5 shows the variance explained by the first and second harmonics for
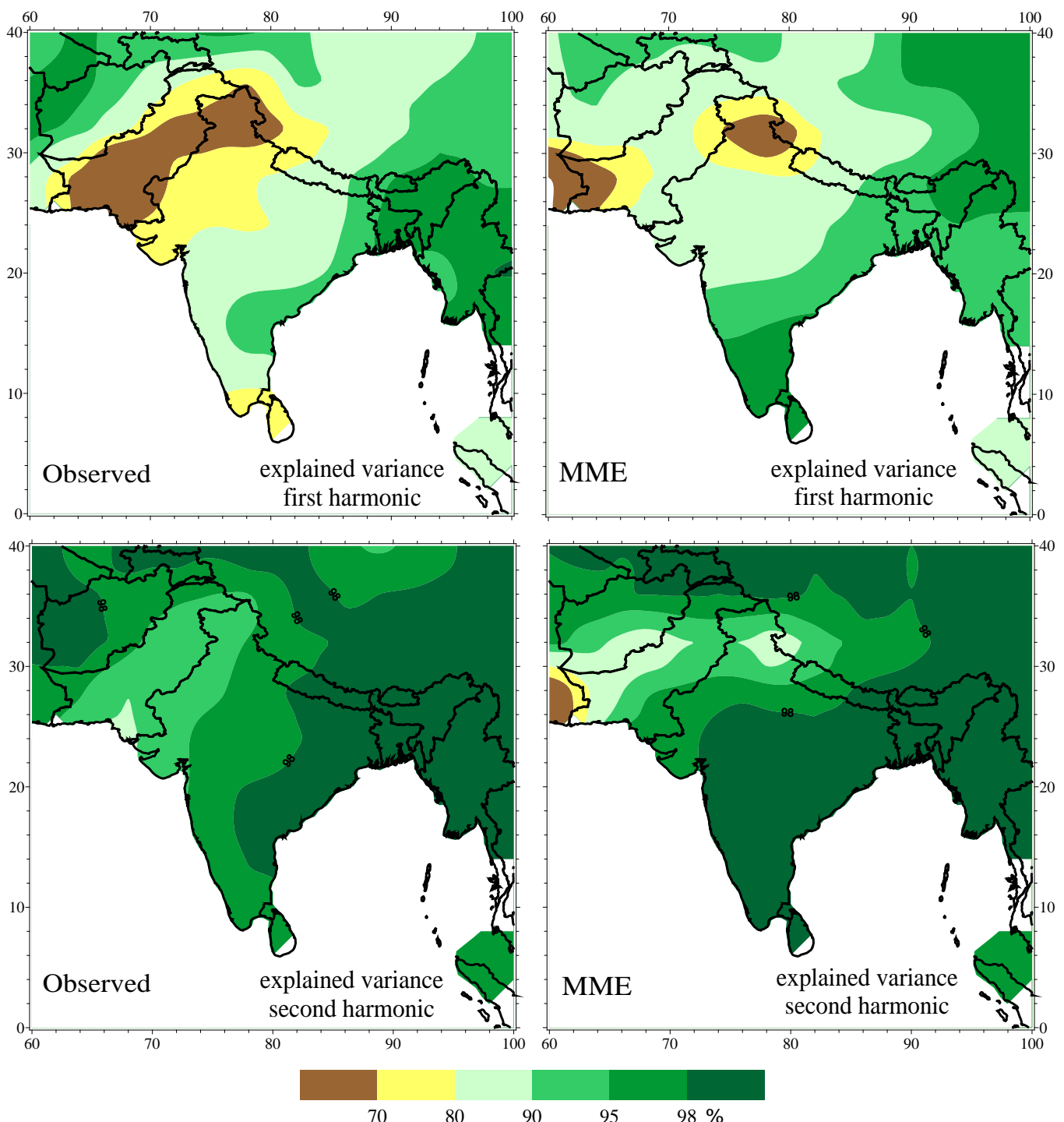

Figure 5. Same as Figure 2, but for the Indian monsoon. 
the annual rainfall. It is very clear from the figure that in the observations the second harmonic explains large variance. Note that the lower figure shows the sum of the variance explained by first and second harmonics. Right hand side figure shows that the model is able to capture the importance of the second harmonic over the Indian monsoon region. Earlier studies, [17] [18] did not include the second harmonic.

Figure 6(a) and Figure 6(b) show that the MME is able to capture very well the amplitude of first and second harmonics. There are some differences only in the northern part. In the case of phase there are differences only in the east and west side with good agreement in the middle.

The RMS and ABSE and bias the models make with respect to observations in determining the amplitude and phase of first four harmonics and mean annual rainfall for the Indian monsoon are given in Table 3. Also given are the spatial CCs between the observed and model amplitudes and phases. The CCs are high for MME and in many cases they are more than 0.8. High CC of 0.92 is found for the amplitude of first harmonic. All the models and MME seem to have same difficulty in reproducing higher harmonics. Just like in the case of global monsoons, the CCs for the phases are high in individual models and MME. This shows models and MME do well in representing the phase of the Indian monsoon such the onset and withdrawal.

\subsection{South American Monsoon}

Figure 7 is again similar to Figure 1. A comparison of top left hand side and middle figures shows that the MME is able to reproduce well the general distribution of rainfall. It is interesting to note that the northeast semi-arid region is reproduced well although there are quantitative differences. The northwestern maximum rainfall over northeast Amazonia is not reproduced. Top right hand side figure show there are large variations amongst the models are over western South America and also over the Sao Paulo, Rio de Janeiro states.

The middle figure shows that the rainfall in the principal summer monsoon month January is reproduced well but there are quantitative differences. The MME has difficulty in reproducing the high rainfall over northwest region of South America. Further it falsely produces a dry region over northern region. The dry region over northeast Brazil is also not reproduced well. The right hand side figure in the middle shows that the all the models falsely reproduce the dry region. There are large differences amongst the models over western South America.

The lower figure shows very good agreement between MME and the observations. The right hand side figure shows all the models perform well in reproducing July rainfall in austral winter. The maximum rainfall noted in the observations over south Brazil is not reproduced in MME.

Figure 8 shows the variance explained by the first harmonic and the total variance explained by the first two harmonics. In the observations one can note the 


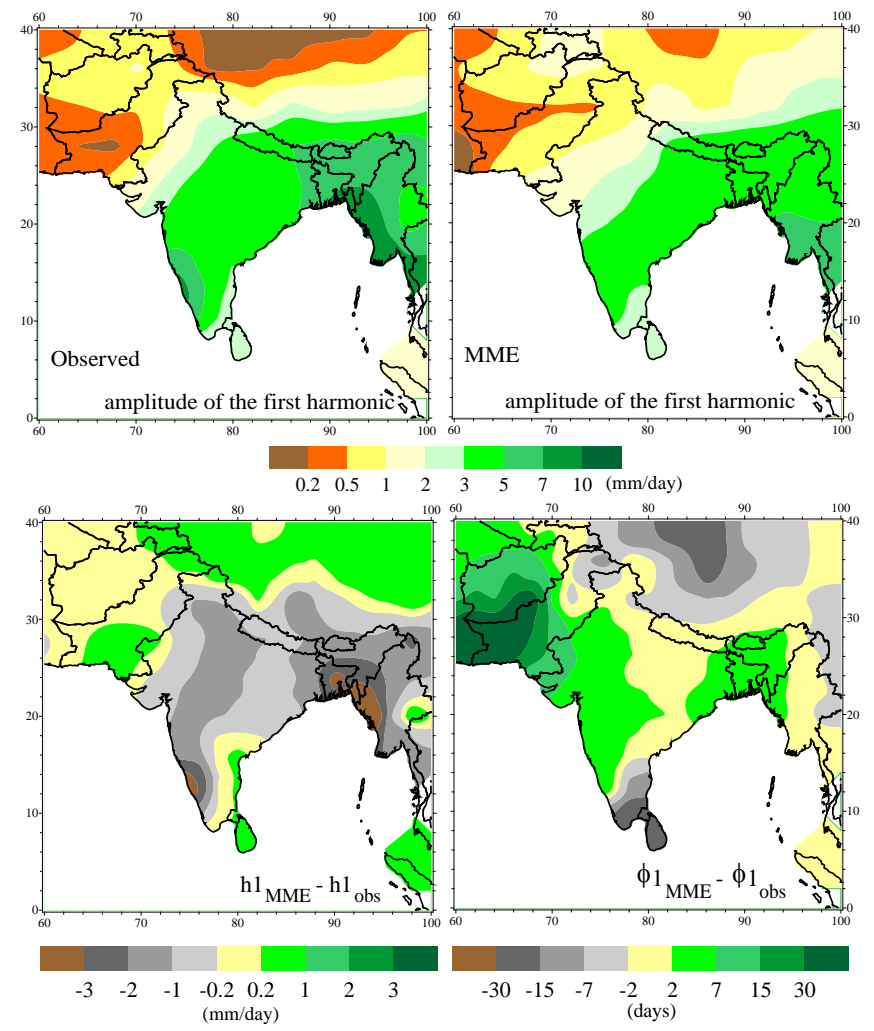

(a)
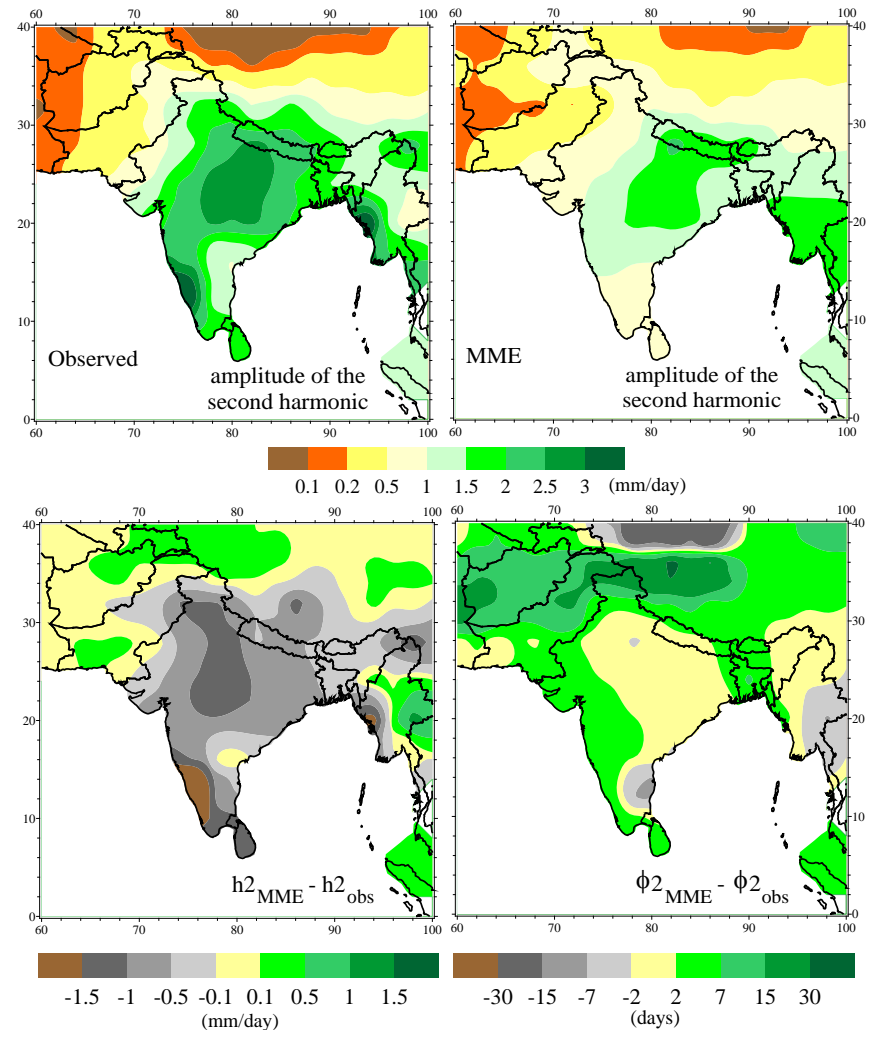

(a)

Figure 6. Same as Figure 3(a) and Figure 3(b), but for the Indian monsoon. 

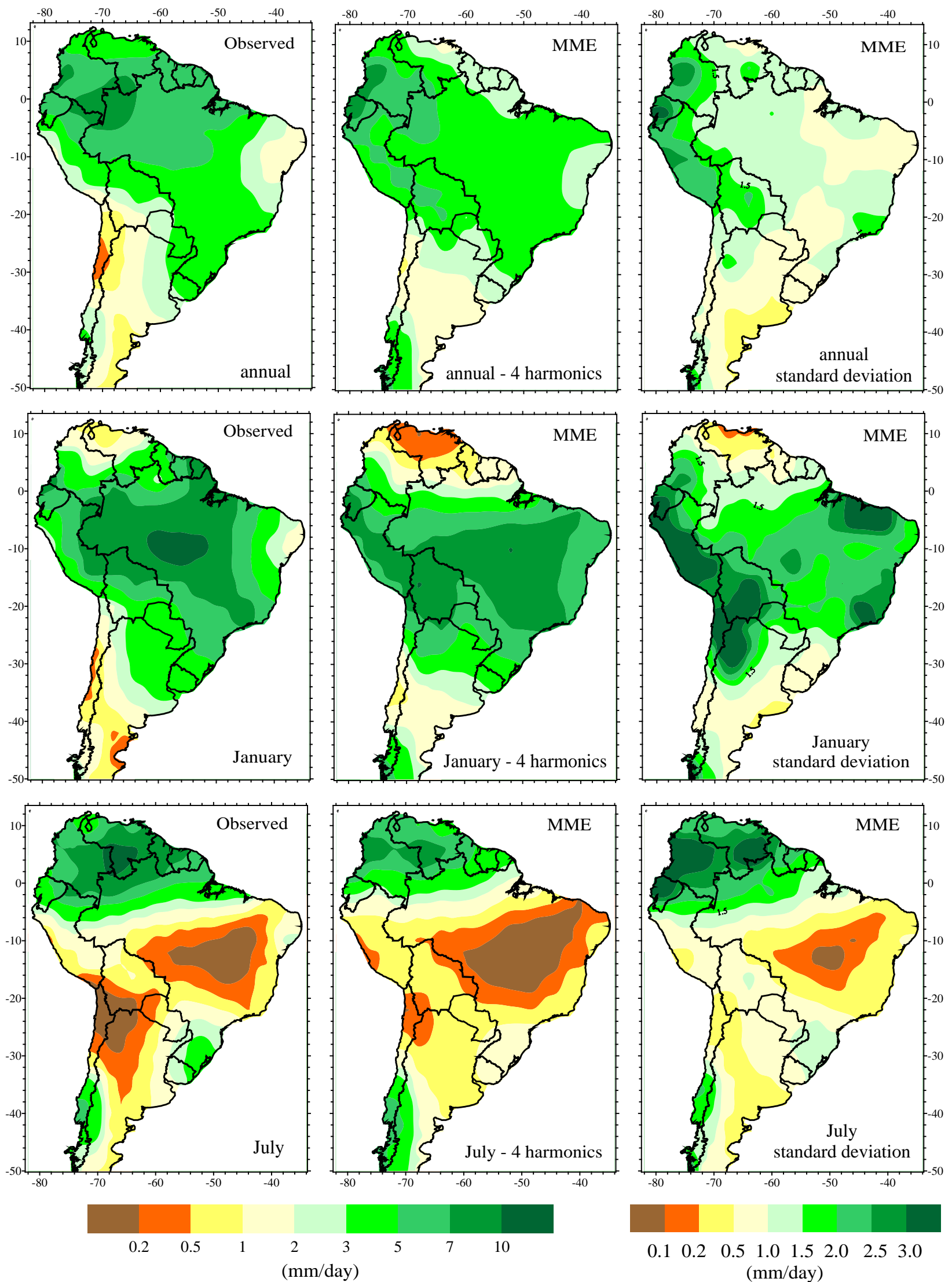

Figure 7. Same as Figure 1, but for the South American monsoon. 

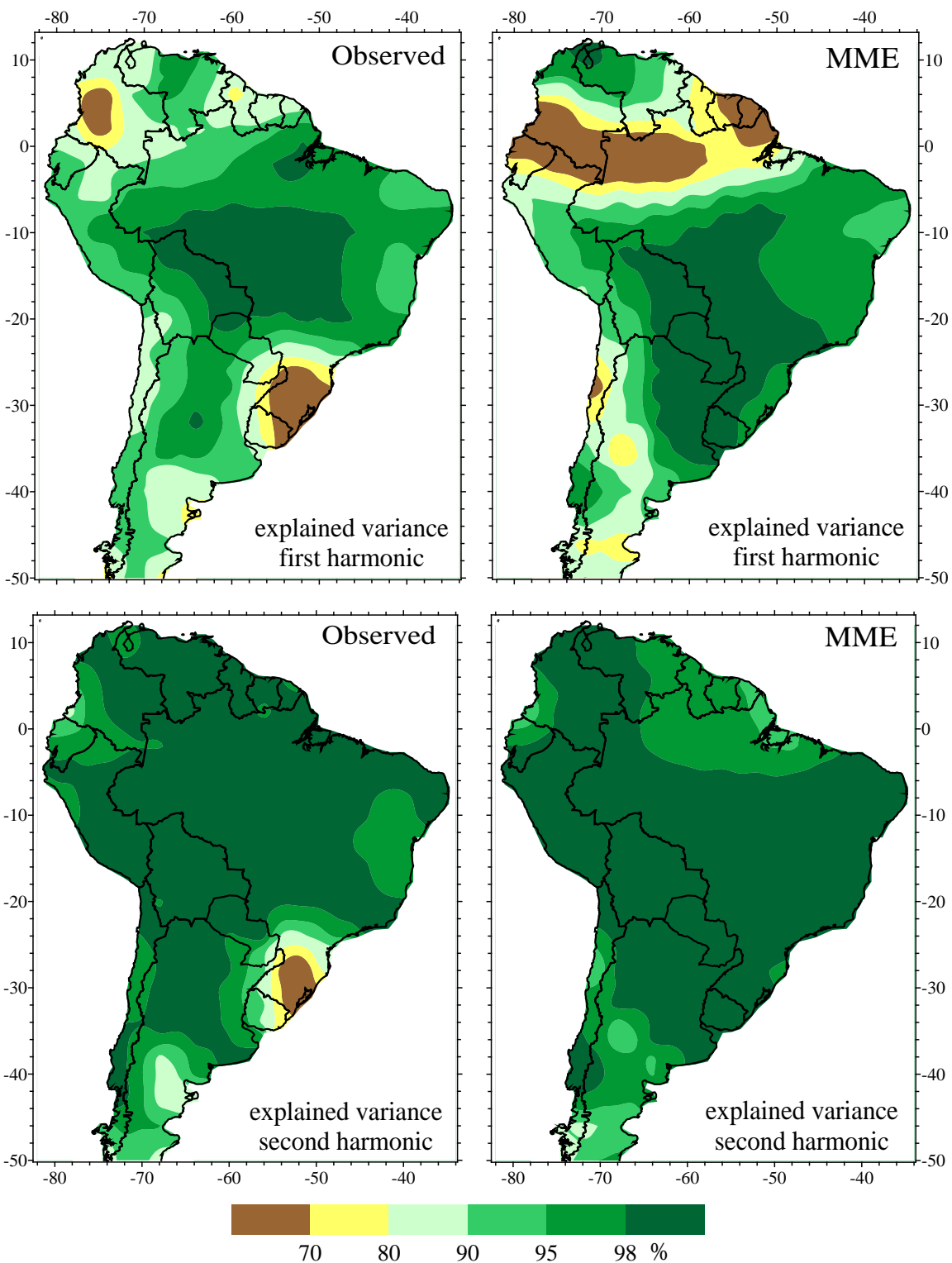

Figure 8. Same as Figure 2, but for the South American monsoon.

importance for the second harmonic. MME is able to reproduce the variance explained by the first two harmonic except over the northwest and southeast South America.

Figure 9(a) and Figure 9(b) show that the MME able to capture the importance of the first harmonic in central Brazil. There are large differences in the MME and observations in middle of South America. But the differences are very less over northern and southern parts in the annual component. In the semi-annual component also the differences are large over eastern and western South America. Regarding the phase except over the region of Mato Grosso and Minas Gerais states the differences are less for the annual harmonic. The differences are very low over northeast Brazil. The differences are large over Argentina for the annual harmonic but the differences are low in the semi-annual 

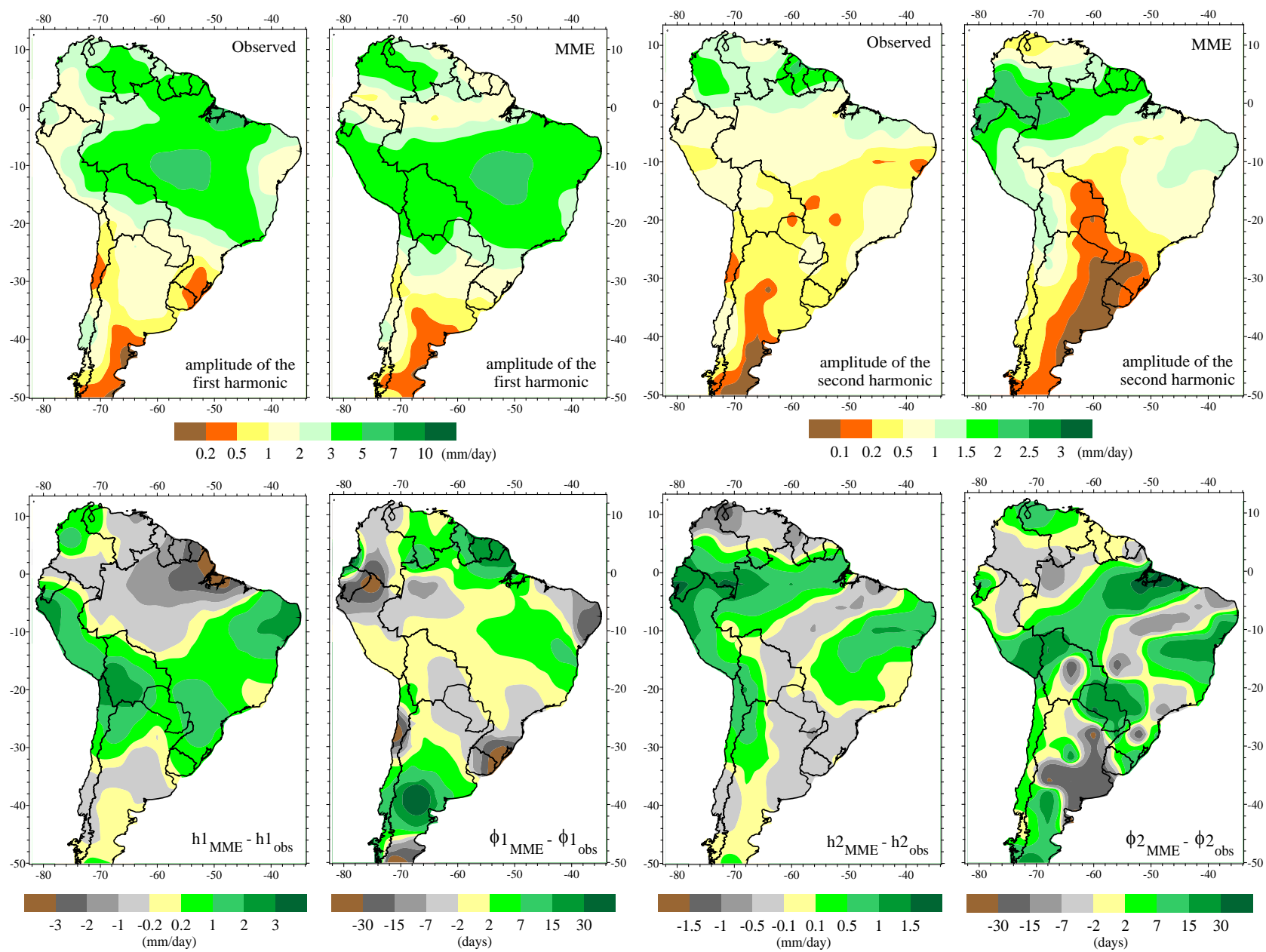

(a)
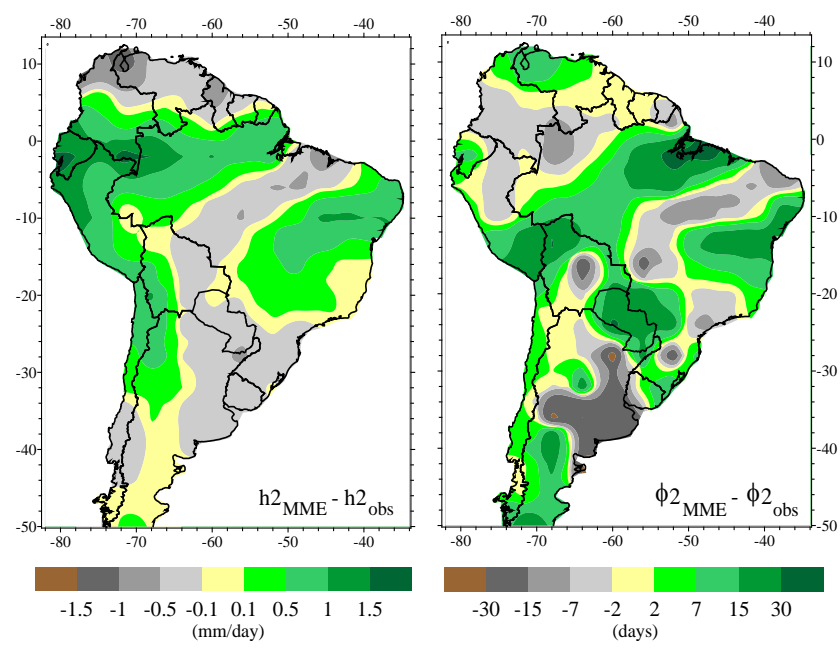

(b)

Figure 9. Same as Figure 3(a) and Figure 3(b), but for the South American monsoon.

harmonic.

Table 4 gives similar to Table 2 and Table 3, the ABSE, RMSE, bias and the correlation. The CCs are small for the amplitudes unlike those of Table 1 and Table 2. But the CCs are very large for the phases just as in the case of global and Indian monsoons. This shows that the MME and individual models are able to capture the phase of South American monsoon such as the onset and withdrawal.

In the above we have seen that the individual models and MME reproduced reasonably well the global monsoons and Indian and South American monsoons. That is they reproduce well the seasonal cycles in rainfall there by suggesting that they are useful in prediction of future climate change and the mitigation adverse climate change.

\section{Conclusions}

To our knowledge, a systematic attempt has not yet been made to assess quantitatively the capability of models in reproduction seasonal cycles in tropical 
V. Brahmananda Rao et al.

Table 3. Same as Table 1, but for the Indian monsoon.

\begin{tabular}{|c|c|c|c|c|c|c|c|c|c|c|c|c|}
\hline \multicolumn{2}{|c|}{ Model } & MIROC3.2 & CCSM3 & HadCM3 & ЕСНАM5 & Mk3.0 & CGCM2.3.2 & CM4 & BCM2.0 & CGCM3 & CM3.0 & MME \\
\hline \multirow{4}{*}{ 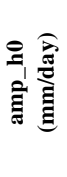 } & Bias & 0.50 & 0.20 & 0.10 & -0.10 & -0.60 & 0.40 & 0.70 & 0.30 & -0.20 & -0.10 & 0.20 \\
\hline & ABSE & 1.10 & 1.10 & 1.20 & 1.20 & 1.10 & 1.00 & 1.80 & 1.30 & 0.90 & 1.10 & 0.70 \\
\hline & RMSE & 1.60 & 1.60 & 1.70 & 1.80 & 1.60 & 1.30 & 2.30 & 1.90 & 1.20 & 1.40 & 0.90 \\
\hline & Correl & 0.78 & 0.73 & 0.78 & 0.69 & 0.80 & 0.83 & 0.42 & 0.63 & 0.78 & 0.71 & 0.89 \\
\hline \multirow{4}{*}{ 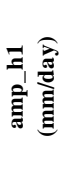 } & Bias & 0.20 & -0.60 & -0.10 & -0.50 & -0.80 & 0.00 & -0.10 & -0.40 & -0.50 & -0.80 & -0.40 \\
\hline & ABSE & 1.30 & 1.40 & 1.50 & 1.40 & 1.40 & 1.10 & 1.90 & 1.50 & 1.10 & 1.40 & 0.90 \\
\hline & RMSE & 2.10 & 2.40 & 2.40 & 2.30 & 2.30 & 1.60 & 2.60 & 2.20 & 1.60 & 2.00 & 1.30 \\
\hline & Correl & 0.75 & 0.63 & 0.69 & 0.68 & 0.73 & 0.81 & 0.39 & 0.61 & 0.80 & 0.69 & 0.92 \\
\hline \multirow{4}{*}{ 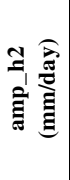 } & Bias & -0.10 & -0.30 & 0.00 & -0.30 & -0.20 & -0.10 & 0.00 & -0.20 & -0.20 & -0.10 & -0.30 \\
\hline & ABSE & 0.70 & 0.80 & 0.80 & 0.70 & 0.80 & 0.70 & 0.90 & 0.80 & 0.60 & 0.80 & 0.50 \\
\hline & RMSE & 1.20 & 1.30 & 1.40 & 1.20 & 1.30 & 0.90 & 1.30 & 1.10 & 0.80 & 1.10 & 0.80 \\
\hline & Correl & 0.58 & 0.46 & 0.51 & 0.54 & 0.48 & 0.63 & 0.16 & 0.48 & 0.64 & 0.44 & 0.77 \\
\hline \multirow{4}{*}{ 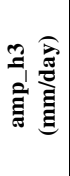 } & Bias & 0.10 & -0.10 & 0.20 & -0.10 & 0.00 & 0.10 & 0.20 & 0.10 & 0.00 & 0.00 & -0.10 \\
\hline & ABSE & 0.40 & 0.40 & 0.50 & 0.30 & 0.30 & 0.40 & 0.50 & 0.40 & 0.30 & 0.40 & 0.20 \\
\hline & RMSE & 0.70 & 0.60 & 0.80 & 0.50 & 0.50 & 0.50 & 0.60 & 0.60 & 0.50 & 0.60 & 0.40 \\
\hline & Correl & 0.46 & 0.33 & 0.32 & 0.50 & 0.52 & 0.52 & 0.24 & 0.31 & 0.18 & 0.18 & 0.66 \\
\hline \multirow{4}{*}{ 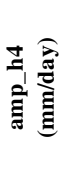 } & Bias & 0.10 & 0.00 & 0.10 & 0.00 & 0.00 & 0.20 & 0.20 & 0.10 & 0.00 & 0.00 & -0.10 \\
\hline & ABSE & 0.30 & 0.20 & 0.30 & 0.20 & 0.20 & 0.30 & 0.30 & 0.20 & 0.10 & 0.20 & 0.10 \\
\hline & RMSE & 0.40 & 0.30 & 0.50 & 0.30 & 0.30 & 0.40 & 0.40 & 0.30 & 0.30 & 0.30 & 0.20 \\
\hline & Correl & 0.45 & 0.46 & 0.29 & 0.65 & 0.50 & 0.47 & 0.12 & 0.42 & 0.39 & 0.37 & 0.47 \\
\hline \multirow{4}{*}{ 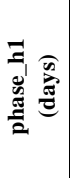 } & Bias & -3.00 & -4.40 & 2.30 & -4.60 & 4.90 & -1.00 & 6.20 & 3.10 & 1.90 & -1.60 & 2.70 \\
\hline & ABSE & 9.70 & 16.90 & 12.50 & 12.50 & 16.70 & 10.10 & 14.00 & 10.90 & 10.60 & 25.50 & 8.40 \\
\hline & RMSE & 17.70 & 27.30 & 19.60 & 21.80 & 22.30 & 18.00 & 24.20 & 21.50 & 18.40 & 35.50 & 16.10 \\
\hline & Correl & 0.86 & 0.72 & 0.85 & 0.82 & 0.79 & 0.84 & 0.68 & 0.78 & 0.87 & 0.68 & 0.87 \\
\hline \multirow{4}{*}{ 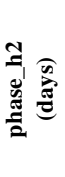 } & Bias & 1.50 & 0.80 & 2.10 & -4.40 & 7.00 & 1.30 & 2.50 & 1.40 & 1.00 & 3.80 & 3.70 \\
\hline & ABSE & 13.10 & 14.10 & 12.30 & 9.60 & 16.00 & 11.50 & 11.90 & 11.40 & 11.20 & 19.70 & 7.90 \\
\hline & RMSE & 18.00 & 19.30 & 17.30 & 14.50 & 20.20 & 16.50 & 17.30 & 16.60 & 15.70 & 24.80 & 13.20 \\
\hline & Correl & 0.79 & 0.76 & 0.84 & 0.85 & 0.73 & 0.78 & 0.83 & 0.85 & 0.81 & 0.63 & 0.89 \\
\hline \multirow{4}{*}{ 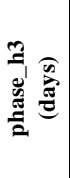 } & Bias & 0.90 & -1.30 & 2.90 & -4.40 & 2.50 & 1.10 & 5.20 & 3.00 & 3.40 & 7.00 & 5.10 \\
\hline & ABSE & 8.60 & 13.60 & 10.00 & 11.00 & 11.50 & 8.50 & 13.50 & 11.60 & 9.80 & 14.30 & 8.20 \\
\hline & RMSE & 11.80 & 16.40 & 13.20 & 13.50 & 14.20 & 10.70 & 16.70 & 14.80 & 12.80 & 16.90 & 11.50 \\
\hline & Correl & 0.72 & 0.74 & 0.75 & 0.66 & 0.73 & 0.76 & 0.48 & 0.65 & 0.55 & 0.69 & 0.63 \\
\hline \multirow{4}{*}{ 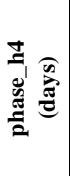 } & Bias & 1.00 & 1.20 & 0.90 & -4.00 & 5.30 & 0.40 & 2.20 & -0.80 & 0.60 & 5.90 & 3.70 \\
\hline & ABSE & 9.50 & 12.00 & 8.50 & 9.70 & 10.50 & 8.50 & 10.50 & 9.20 & 10.70 & 11.60 & 8.60 \\
\hline & RMSE & 11.60 & 13.70 & 10.10 & 11.50 & 12.30 & 10.30 & 12.50 & 11.70 & 13.00 & 13.00 & 10.60 \\
\hline & Correl & 0.81 & 0.68 & 0.88 & 0.85 & 0.81 & 0.86 & 0.85 & 0.82 & 0.81 & 0.80 & 0.87 \\
\hline \multirow{2}{*}{$\begin{array}{l}\text { grid } \\
\text { size }\end{array}$} & long $^{\circ}$ & 1.125 & 1.40 & 1.825 & 1.825 & 1.825 & 2.81 & 2.81 & 2.81 & 3.75 & 5.00 & 3.75 \\
\hline & lat $^{\circ}$ & 1.120 & 1.40 & 1.250 & 1.860 & 1.860 & 2.81 & 2.81 & 2.81 & 3.75 & 4.00 & 3.75 \\
\hline
\end{tabular}

precipitation. Since seasonal cycles exhibit climate change, models can predict climate change accurately only when they reproduce seasonal cycles accurately. Seasonal cycles in tropical precipitation are known as monsoons.

In this paper, we use a suite of 10 state-of-art models and observations to evaluate how accurately the models reproduce seasonal cycles in tropical precipitation or monsoons. Earlier studies of monsoons use only the first harmonic of 
Table 4. Same as Table 1, but for the South American monsoon.

\begin{tabular}{|c|c|c|c|c|c|c|c|c|c|c|c|c|}
\hline \multicolumn{2}{|c|}{ Model } & MIROC3.2 & CCSM3 & HadCM3 & ЕСНАM5 & Mk3.0 & CGCM2.3.2 & CM4 & ВСM2.0 & CGCM3 & CM3.0 & MME \\
\hline \multirow{4}{*}{ 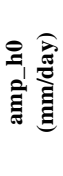 } & Bias & 0.10 & -0.50 & 0.90 & -0.60 & -1.10 & -0.50 & 0.10 & 0.00 & -0.70 & -1.10 & -0.20 \\
\hline & ABSE & 1.60 & 1.60 & 1.70 & 1.40 & 1.90 & 1.60 & 1.70 & 1.90 & 1.60 & 1.80 & 1.30 \\
\hline & RMSE & 2.40 & 2.10 & 3.00 & 2.00 & 2.60 & 2.10 & 2.30 & 2.60 & 2.20 & 2.10 & 1.70 \\
\hline & Correl & 0.50 & 0.55 & 0.52 & 0.59 & 0.34 & 0.47 & 0.44 & 0.30 & 0.43 & 0.57 & 0.61 \\
\hline \multirow{4}{*}{ 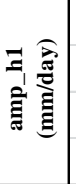 } & Bias & 0.80 & 0.30 & 1.00 & -0.20 & 0.20 & 0.80 & 0.50 & 0.60 & -0.20 & -0.10 & 0.20 \\
\hline & ABSE & 1.30 & 1.40 & 1.50 & 1.20 & 1.40 & 1.20 & 1.60 & 1.50 & 1.00 & 1.10 & 1.00 \\
\hline & RMSE & 2.00 & 1.90 & 2.40 & 1.60 & 1.90 & 1.70 & 2.10 & 2.10 & 1.40 & 1.50 & 1.30 \\
\hline & Correl & 0.57 & 0.44 & 0.59 & 0.52 & 0.42 & 0.69 & 0.46 & 0.45 & 0.61 & 0.52 & 0.67 \\
\hline \multirow{4}{*}{ 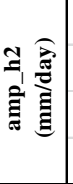 } & Bias & 0.50 & 0.30 & 0.30 & 0.30 & 0.30 & 0.50 & 0.40 & 0.70 & 0.20 & 0.20 & 0.20 \\
\hline & ABSE & 0.70 & 0.60 & 0.60 & 0.50 & 0.70 & 0.70 & 0.70 & 0.80 & 0.50 & 0.40 & 0.50 \\
\hline & RMSE & 1.10 & 0.80 & 1.00 & 0.70 & 1.00 & 1.10 & 1.10 & 1.20 & 0.70 & 0.50 & 0.60 \\
\hline & Correl & 0.49 & 0.34 & 0.39 & 0.51 & 0.27 & 0.43 & 0.24 & 0.41 & 0.35 & 0.66 & 0.48 \\
\hline \multirow{4}{*}{ 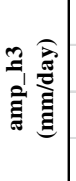 } & Bias & 0.20 & 0.30 & 0.20 & 0.10 & 0.20 & 0.40 & 0.20 & 0.30 & 0.10 & 0.20 & 0.10 \\
\hline & ABSE & 0.30 & 0.40 & 0.30 & 0.30 & 0.40 & 0.50 & 0.30 & 0.40 & 0.30 & 0.30 & 0.20 \\
\hline & RMSE & 0.50 & 0.60 & 0.50 & 0.40 & 0.50 & 0.60 & 0.40 & 0.50 & 0.40 & 0.40 & 0.30 \\
\hline & Correl & 0.31 & 0.28 & 0.38 & 0.18 & 0.26 & 0.13 & 0.19 & 0.28 & 0.19 & 0.23 & 0.29 \\
\hline \multirow{4}{*}{ 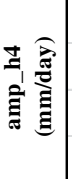 } & Bias & 0.10 & 0.00 & 0.10 & 0.00 & 0.10 & 0.20 & 0.00 & 0.10 & 0.00 & 0.00 & -0.10 \\
\hline & ABSE & 0.20 & 0.20 & 0.20 & 0.20 & 0.20 & 0.30 & 0.20 & 0.20 & 0.10 & 0.10 & 0.10 \\
\hline & RMSE & 0.30 & 0.30 & 0.30 & 0.20 & 0.30 & 0.40 & 0.30 & 0.30 & 0.20 & 0.20 & 0.20 \\
\hline & Correl & 0.30 & 0.21 & 0.28 & 0.27 & 0.22 & 0.27 & 0.16 & 0.26 & 0.18 & 0.17 & 0.21 \\
\hline \multirow{4}{*}{ 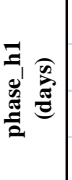 } & Bias & -1.30 & 1.00 & 1.30 & -1.90 & 2.40 & -2.60 & -0.90 & 0.50 & -2.40 & -2.80 & -1.40 \\
\hline & ABSE & 9.50 & 15.70 & 11.60 & 15.90 & 12.30 & 11.90 & 12.60 & 12.60 & 17.10 & 10.90 & 9.10 \\
\hline & RMSE & 16.20 & 25.30 & 19.00 & 25.00 & 19.90 & 19.00 & 21.50 & 20.10 & 26.30 & 15.50 & 17.30 \\
\hline & Correl & 0.97 & 0.94 & 0.96 & 0.94 & 0.95 & 0.96 & 0.95 & 0.96 & 0.93 & 0.97 & 0.97 \\
\hline \multirow{4}{*}{ 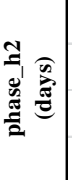 } & Bias & -0.10 & 2.30 & 2.70 & 1.50 & 2.90 & 1.90 & 2.00 & 0.70 & 6.20 & 1.80 & 4.60 \\
\hline & ABSE & 14.50 & 20.20 & 12.40 & 16.30 & 15.40 & 14.80 & 17.10 & 17.40 & 17.90 & 12.10 & 13.90 \\
\hline & RMSE & 19.00 & 23.80 & 16.70 & 19.80 & 19.90 & 18.50 & 22.10 & 22.00 & 21.90 & 16.20 & 18.00 \\
\hline & Correl & 0.79 & 0.79 & 0.86 & 0.77 & 0.79 & 0.78 & 0.73 & 0.73 & 0.79 & 0.80 & 0.82 \\
\hline \multirow{4}{*}{ 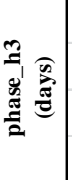 } & Bias & -0.80 & 0.30 & 1.50 & -2.20 & 1.30 & -3.00 & 3.00 & 2.20 & 3.60 & 0.00 & 0.00 \\
\hline & ABSE & 9.10 & 11.40 & 9.70 & 10.30 & 9.40 & 9.10 & 10.30 & 10.70 & 12.40 & 9.00 & 7.00 \\
\hline & RMSE & 11.80 & 14.10 & 12.50 & 13.00 & 11.60 & 11.30 & 13.00 & 13.40 & 14.90 & 11.30 & 9.10 \\
\hline & Correl & 0.77 & 0.72 & 0.79 & 0.73 & 0.76 & 0.78 & 0.78 & 0.76 & 0.75 & 0.83 & 0.86 \\
\hline \multirow{4}{*}{ 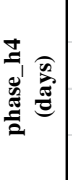 } & Bias & -0.70 & -1.40 & 1.60 & -1.60 & -0.10 & -2.00 & 1.50 & 2.70 & -0.70 & 1.50 & -0.80 \\
\hline & ABSE & 9.20 & 11.30 & 10.40 & 9.50 & 10.10 & 10.20 & 12.50 & 10.30 & 10.00 & 10.70 & 9.10 \\
\hline & RMSE & 11.00 & 13.10 & 12.30 & 11.30 & 11.80 & 11.90 & 13.80 & 12.00 & 11.80 & 12.50 & 10.60 \\
\hline & Correl & 0.73 & 0.69 & 0.69 & 0.70 & 0.74 & 0.68 & 0.69 & 0.75 & 0.63 & 0.76 & 0.73 \\
\hline \multirow{2}{*}{$\begin{array}{l}\text { grid } \\
\text { size }\end{array}$} & long $^{\circ}$ & 1.125 & 1.40 & 1.825 & 1.825 & 1.825 & 2.81 & 2.81 & 2.81 & 3.75 & 5.00 & 3.75 \\
\hline & lat $^{\circ}$ & 1.120 & 1.40 & 1.250 & 1.860 & 1.860 & 2.81 & 2.81 & 2.81 & 3.75 & 4.00 & 3.75 \\
\hline
\end{tabular}

yearly (12 months) rainfall. Seasonal cycles can be reproduced only with at least first two harmonics. We calculated the root mean square error, absolute error and bias the models make with respect to observations in reproducing first four harmonics of 12 months cycle. We find that the individual models and also the multi model ensemble reproduce reasonably well the seasonal cycles in rainfall thus suggesting their utility in climate prediction and simulation of global and 
regional monsoons.

\section{References}

[1] Lorenz, E.N. (1968) Climate Determinism. Meteorological Monographs, 5.

[2] Haber, M. and Knutti, R. (2012) Anthropogenic and Natural Warning Inferred from Changes in Earth's Energy Balance. Nature Geosciences, 5, 31-36. https://doi.org/10.1038/ngeo1327

[3] Schneider, S.H. and Dickinson, R.E. (1974) Climate Modelling. Reviews of Geophysics, 12, 447-493. https://doi.org/10.1029/RG012i003p00447

[4] Stine, A.R., Huybers, P. and Fung, I.Y. (2009) Changes in the Phase of the Annual Cycle of Surface Temperature. Nature, 457, 435-440.

https://doi.org/10.1038/nature07675

[5] K-1 Model Developers (2004) K-1 Coupled Model (MIROC) Description, K-1 Technical Report. In: Hasumi, H. and Emori, S., Eds., Center for Climate System Research, University of Tokyo, $34 \mathrm{p}$.

[6] Collins, W.D., Bitz, C.M., Blackmon, M.L., Bonan, G.B., Bretherton, C.S., Carton, J.A., Chang, P., Doney, S.C., Hack, J.J., Henderson, T.B., Kiehl, J.T., Large, W.G., McKenna, D.S., Santer, B.D. and Smith, R.D. (2006) The Community Climate System Model Version 3 (CCSM3). Journal of Climate, 19, 2122-2143. https://doi.org/10.1175/JCLI3761.1

[7] Jones, C.D., Gregory, J.M., Thorpe, R.B., Cox, P.M., Murphy, J.M., Sexton, D.M.H. and Valdes, P. (2004) Systematic Optimisation and Climate Simulation of FAMOUS, a Fast Version of HadCM3. Hadley Centre Technical Note 60, Hadley Centre, Exeter.

[8] Roeckner, E., Bäuml, G., Bonaventura, L., Brokopf, R., Esch, M., Giorgetta, M., Hagemann, S., Kirchner, I., Kornblueh, L., Manzini, E., Rhodin, A., Schlese, U., Schulzweida, U. and Tompkins, A. (2003) The Atmospheric General Circulation Model ECHAM 5. PART I: Model Description. Max Planck Institute for Meteorology Rep. 349, 127 p.

[9] Gordon, H.B., Rotstayn, I.D., McGregor, J.I., Dix, M.R., Kowalezyk, O’Farrell, S.P., Waterman, I.J., Hirst, A.C., Wilson, S.G., Collier, M.A., Watterson, I.G. and Elliot, T.I. (2002) The CSIRO Mk3 Climate System Model. Asoendale: CSIRO Atmospheric Research Technical Paper No. 60.

[10] Yukimoto, S., et al. (2001) The New Meteorological Research Institute Coupled GCM (MRI-CGM2)-Model Climate and Variability. Meteorology and Geophysics, 52, 47-88. https://doi.org/10.2467/mripapers.51.47

[11] Marti, O., Braconnot, P., Bellier, J., Benshila, R., Bony, S., Brockmann, P., Cadule, P., Caubel, A., Denvil, S., Dufresne, J.L., Fairhead, L., Filiberti, M.-A., Foujols, M.-A., Fichefet, T., Friedlingstein, P., Goosse, H., Grandpeix, J.Y., Hourdin, F., Krinner, G., Lévy, C., Madec, G., Musat, I., de Noblet, N., Polcher, J. and Talandier, C. (2005) The New IPSL Climate System Model: IPSL-CM4. Note du Pôle de Modélisation, 26, 1-86.

[12] Furevik, T., Bentsen, M., Drange, H., Kindem, I.K.T., Kvansto, N.G. and Sorteberg, A. (2003) Description and Evaluation of the Bergen Climate Model: ARPEGE Coupled with MICOM. Climate Dynamics, 21, 27-51. https://doi.org/10.1007/s00382-003-0317-5

[13] McFarlane, N.A., Scinocca, J.F., Lazare, M., Harvey, R., Verseghy, D. and Li, J. (2005) The CCCma Third Generation Atmospheric General Circulation Model. CCCma Internal Report, 25 p. 
[14] Diansky, N.A. and Volodin, E.M. (2002) Simulation of Presente-Day Climate with a Coupled Atmosphere-Ocean General Circulation Model. Izvestiya Atmospheric and Oceanic Physics, 38, 732-747.

[15] (1950-1999) Monthly and Annual Time Series (Version 1.02) Centre for Climatic Research, Department of Geography, University of Delaware.

[16] Whittaker, E. and Robbinson, G. (1967) The Calculus of Observations. Dover, Mineola, New York, 397 p.

[17] Lee, J.L., Wang, B., Kang, I.S., Shukla, J., Kumar, A., Kuj, J.S., Scheman, J.K.E., Luo, J.J., Yamagata, T., Fu, X., Alles, O., Stezn, B., Rosati, T. and Park, C.K. (2010) How Are Seasonal Prediction Skills Related to Models' Performance on Mean State and Annual Cycle? Climate Dynamics, 35, 267-283.

https://doi.org/10.1007/s00382-010-0857-4

[18] Wang, B. and Qinguha, D. (2008) Global Monsoon: Dominant Mode of Annual Variations in the Tropics. Dynamics of Atmosphere and Oceans, 44, 165-183.

[19] Hsu, C.P. and Wallace, J.M. (1976) The Global Distribution of the Annual and Semiannual Cycles in Rainfall. Monthly Weather Review, 104, 1903-1101. 